\title{
Editorial \\ New Section of Acta Crystallographica
}

The number of publications reporting crystal structures of biological macromolecules is rapidly increasing in the scientific literature. These articles cover both structural results and the development of new methods to help solve and interpret the crystal structures. To accommodate this expanding area, a new section of Acta Crystallographica devoted to biological crystallography will be published, beginning with Volume 49 in January 1993.

Macromolecular crystallography is now a highly significant area of crystallographic research and therefore the initiation of Section $D$ is in keeping with the original aim of P. P. Ewald when he founded Acta Crystallographica in 1948 as the central place for the publication and discussion of crystallographic research. He expressed in the Editorial Preface the hope that 'Acta will focus international discussion of problems of crystallography'. The establishment of a separate section devoted to the discussion of macromolecular structures is clearly both an appropriate and a necessary means of preserving this goal.

The suggestion for an additional section evolved from the results of a questionnaire circulated to more than 400 crystallographers in October 1990. A Working Party established to examine this project met in Chester on 8 March 1991 at which time the need for a new section was discussed. The establishment of the new section of Acta Crystallographica was approved by the IUCr Executive Committee in August 1991.

The four sections of Acta Crystallographica from January 1993 will be:

Section A - Foundations of Crystallography

Section B - Structural Science

Section C - Crystal Structure Communications

Section D - Biological Crystallography.

Most articles on methods and theory relevant to macromolecular structure determinations will remain in Section $\mathrm{A}$ while articles reporting structures of biological molecules will be published in Section D.

The Editor of Section D will be Dr Jenny P. Glusker, who will work closely with Professor C. E. Bugg, the Editor-in-Chief of Acta Crystallographica. New members of the Acta Crystallographica Editorial Board will be appointed together with an Advisory Committee for this new section. Publication will begin in January 1993 and all current subscribers to Acta Crystallographica Sections A or B will receive gratis copies of Acta Crystallographica Section D for one year. After that time individual sub- scriptions for Acta Crystallographica Section D may be made.

\section{Call for papers}

Section D of Acta Crystallographica now welcomes the submission of manuscripts based on structures of biological macromolecules. A detailed set of instructions to authors is being prepared and will use a set of criteria for reporting structures that has been developed by the $\mathrm{IUCr}$ Commission on Biological Macromolecules and the IUCr Commission on Journals. Some solicited Lead Articles will be included as well as reports of meetings. Prospective authors may find useful the following information in preparing manuscripts:

1. Preliminary data on unit-cell dimensions and space groups will be considered for publication, provided suitable diffraction photographs (or their equivalent), together with an estimate of resolution, are included.

2. Articles on crystal growth of biological macromolecules will be welcomed.

3. For all structural studies, coordinates and structure factors must be deposited with the Protein Data Bank at Brookhaven National Laboratory.

4. For all papers, sufficient experimental evidence should be provided to convince the referees that the interpretations of the diffraction data and electron-density maps are correct, within the resolution of the analysis.

5. Refinements of known structures may be published if the information content warrants it.

6. Colour figures will, in the first two years, be printed free of charge to authors.

7. Three copies of the manuscript and the diagrams and one signed Transfer of Copyright Agreement form should be submitted to the Editor or Co-editor together with a covering letter.

8. The overall format will be similar to that for Sections $\mathrm{A}$ and $\mathrm{B}$ of Acta Crystallographica.

Articles for submission should be sent to:

Dr Jenny P. Glusker,

The Institute for Cancer Research,

The Fox Chase Cancer Center, 7701 Burholme Avenue,

Philadelphia,

PA 19111, USA

Phone: (215) 728-2220

FAX: (215) 728-3574

(INTERNET) Glusker@fccc.edu 